\title{
Factors Influencing Preferences and Adoption of Improved Groundnut Varieties among Farmers in Tanzania
}

\author{
Serapius Mwalongo ${ }^{1,2}$, Essegbemon Akpo ${ }^{1,3, *}$, Gerald Alex Lukurugu ${ }^{2}$, Geoffrey Muricho ${ }^{1}$, \\ Ronnie Vernooy ${ }^{4}{ }^{\mathbb{D}}$, Athanas Minja ${ }^{2}$, Christopher Ojiewo ${ }^{1}$, Esther Njuguna ${ }^{1}$, Gloria Otieno ${ }^{5} \mathbb{C}$ \\ and Rajeev Varshney ${ }^{1}$ (D) \\ 1 International Crops Research Institute for the Semi-Arid Tropics, Patancheru 502 324, India; \\ mwalongoserapius1986@gmail.com (S.M.); G.Muricho@cgiar.org (G.M.); C.Ojiewo@cgiar.org (C.O.); \\ E.Njuguna@cgiar.org (E.N.); R.K.Varshney@cgiar.org (R.V.) \\ 2 Tanzania Agricultural Research Institute, 41000 Dodoma, Tanzania; sumbanya@yahoo.com (G.A.L.); \\ athanasminja2016@gmail.com (A.M.) \\ 3 "Ecole de Gestion et de Production Végétale et Semencière, Université Nationale d'Agriculture", \\ BP 43 Kétou, Benin \\ 4 Alliance of Bioversity International and CIAT, c/o Wageningen University and Research, \\ 6708 PB Wageningen, The Netherlands; r.vernooy@cgiar.org \\ 5 Alliance of Bioversity International and CIAT, P.O. Box 24384 Kampala, Uganda; g.otieno@cgiar.org \\ * Correspondence: akpo.essegbemon@gmail.com or E.Akpo@cgiar.org
}

Received: 28 July 2020; Accepted: 19 August 2020; Published: 27 August 2020

\begin{abstract}
Access and use of seed of improved varieties of groundnut among farmers can improve farmers' livelihoods and contribute to the potential of crop production in Tanzania. This paper analyzes factors underpinning the adoption of improved groundnut varieties among farmers to pave the way for upscaling quality seed used for increased production and commodity business in farming communities. A four-stage stratified sampling was used to collect data from 300 groundnut farmers in seven agro-ecological zones through individual interviews. Secondary data were collected from the literature and the Tanzania Agricultural Research Institute at Naliendele centre (TARI-Naliendele). Descriptive statistics and Probit regression model were used for data analysis. The empirical results showed that Johari 1985, Pendo 1998, Naliendele 2009, Mnanje 2009, Mangaka 2009 and Nachi 2015, are the main six improved groundnut varieties used by farmers, with Pendo 1998 having the highest adoption rate (17.1\%). In the grain market, four varieties, namely Pendo 1998, Mnanje 2009, Nachi 2015 and Johari 1985, were observed to be highly preferred by grain off-takers. Furthermore, among the adopted improved varieties, Nachi 2015, is observed to be the most consistent high yielding variety, ranging from $1100 \mathrm{~kg} / \mathrm{ha}$ to $1500 \mathrm{~kg} / \mathrm{ha}$ in all agro-ecological zones. A farmer's decision to adopt new varieties is affected by age and gender, farmer group membership, availability of improved seed and seed cost. Overall, male farmers are more likely to adopt improved varieties of groundnut than female farmers. The implications of these findings are also discussed, in particular in the area of policy support.
\end{abstract}

Keywords: adoption; quality seed; groundnut productivity; smallholder farmers; Tanzania

\section{Introduction}

Over the past two decades, poverty has remained high, particularly in sub-Saharan Africa (about $30 \%$ of the total population) [1]. In the entire period, the share of people living on less than USD 1 a day in this region exceeded that in the poorest region of South Asia by about $17 \%$. It is estimated that 
more than $50 \%$ of the people living in sub-Saharan Africa are employed in agriculture [1]. Therefore, investing in agriculture could contribute significantly to reduce poverty here. Although agriculture in the past two decades has been challenged by increasing drought, market shifts, and biotic and abiotic stresses [2], experience indicate that improved varieties can overcome these challenges, including for the case of groundnut [3].

Groundnut is one of the most important annual crops in the world, rich in food nutrients with about $20 \%$ protein, $40 \%$ oil, minerals, and vitamins [3]. It is estimated that, at the farm level, at least $23 \%$ of households in developing countries are employed in groundnut production [4]. In some developing countries, groundnut contributes to about 25 to $60 \%$ of the small-scale farmer's income [5]. In Tanzania, groundnut is one of the main annual crops [4]. It can be produced in all areas with an altitude below $1500 \mathrm{~m}$ and with alluvial soils [6]. These areas are either semi-arid or arid and mostly challenged by drought, food insecurity, and poverty [6]. The production cost of groundnut is lower than that of other annual crops, such as rice [6]. The total production cost of groundnut ranges from 500,000 Tsh/ha to 1,000,000 Tsh/ha compared to rice, which ranges from 2,500,000 Tsh/ha to 3,250,000 Tsh/ha (USD 1 equals about 2325 Tsh) [6,7]. In recent times, the country increasingly has had to cope with market shifts, drought and other biotic and abiotic stresses [2]. To cope with these challenges and improve people's incomes and food needs, the research institute of Tanzania released six improved groundnut varieties in the 1960s and 1990s [8]. The results in productivity were a maximum average of $444 \mathrm{~kg} / \mathrm{ha}$, below expectations during the period [8]. Thereafter, from 2007 to 2019, 11 more improved varieties were released, and productivity increased to an average of $745 \mathrm{~kg} / \mathrm{ha}$. This is still less than the average productivity in Africa, which is $800 \mathrm{~kg} / \mathrm{ha}$ [9-11].

Even though the new varieties were available, it was reported that about $81 \%$ of the groundnut producers still used old varieties, which are less resistant to drought and diseases (e.g., foliar disease), have low productivity and low market value [12]. The price for certified seed varied from 2317 to $4634 \mathrm{Tsh} / \mathrm{kg}$, which is much lower than $5000 \mathrm{Tsh} / \mathrm{kg}$ for rice [13]. It is understood that improved varieties will create long-term benefits. The groundnut market is expanding in Tanzania, due to a rapid population growth rate of 3.1 per year, the multiple uses of groundnut, and exports of about 20,000 tons per year $[14,15]$. Considering the promising demand forecast, it is important to understand the factors hindering farmers to use improved groundnut varieties. Unfortunately, recent literature about this subject is limited.

Research carried out on factors hindering the adoption of new technology in developing countries can be grouped into three broad categories [16]. These categories are: (i) factors related to the characteristics of farmers, (ii) factors related to the characteristics and relative performance of the technology, and (iii) communication of the new technologies. The factors related to the characteristics of farmers include educational level, experience in the activity, age, gender, technology availability, farm size, and labour availability [16]. The factors related to the characteristics and performance of the technology include the economic functions of the product and farmers' perceptions of the new technology. The complexity/simplicity of the new technology, relative advantage, trialability, and observability are also important. Likewise, effective communication channels able to transfer quality information on the technology and market accessibility play important roles.

Concerning social characteristics, evidence indicate that age of the farmer negatively affects the decision to adopt improved variety, while education, farming experience, and extension contact are positive contributors [17]. However, the literature also reported age to positively affect the adoption of new technology [18]. An analysis of the socio-economic determinants of adoption of improved groundnut varieties in Nigeria through the probit regression method found that adoption is largely explained by age and education of household head, and household size [19]. In Kwara State of Nigeria, a study conducted to identify factors which influence adoption, found that labour, age, education, farming experience, and sex significantly affected rice variety adoption [20]. Other reported factors included knowledge of rice cultivation, availability of seed, existence of farmer groups, information 
availability about improved varieties from input dealers, extension officers, and through mobile phones [18].

Other studies indicated that group effects are important for individual decisions, and that, in the particular context of agricultural innovations, farmers share information and learn from each other [20]. Individual adoption decisions depend on the choices of others in the same social groups. Since farmers anticipate that they will share information with others, they are expected to be more likely to adopt when they know many other adopters. One factor that has not received much attention in the literature is the time of the existence of a technology, which can influence adoption at scale in an area [21].

In Tanzania, a study was conducted in Tabora region to determine the factors limiting production of improved groundnut. It was found that limited extension services and labour affected production [17]. Another Tanzanian study was conducted to analyse the gender yield gap between male and female farmers in groundnut production, computing the adoption rate by agro-ecological zones, age, and sex [12]. These studies do not adequately capture factors such as innovation motivation, time lag, communication channels and social characteristics. In general, the scope of these studies was narrow. To provide a more in-depth analysis of adoption, the present study was carried out to identify a broad range of factors and their probability to influence decision making among a larger number of farmersusing the theory of diffusion. All the seven agro-ecologies of Tanzania were surveyed, i.e., South zone, Southern Highlands, Central Zone, Lake Zone, Nothern Highlands, Coastal Zone, and western Zone. The findings could be useful to inform the implementation of new projects, the delivery of more effective extension services and the 2025 government vision of transforming the citizens to at least middle-income earners [8]. The study first identified the improved groundnut varieties and their preferences among farmers in Tanzania. Second, it determined the rate of adoption by type of improved groundnut varieties. Third, it analyzed the key factors influencing the adoption of improved and recently released varieties of groundnut among farmers.

\section{Materials and Methods}

\subsection{Conceptual Framework}

The research design applied the theory of diffusion, which explains the five sequential processes of how a farmer adopts new technology and the factors that can affect the whole adoption process or an event in the adoption process [21] (p. 518). The nature of adopting improved groundnut varieties by farmers is analyzed along the five diffusion stages. The first stage concerns knowledge dissemination to farmers about a new variety. The second stage is about persuasion of farmers; the third involves adoption or abandonment. The fourth stage is about implementation and the last stage is confirmation. The theory of diffusion is also capable of revealing and testing the underlying factors affecting the farmer's decision to adopt new technologies [21]. This research design used four factors of the theory of diffusion (nature of innovation, time, communication channels, and characteristics of a social system), which were translated into survey questions.

We investigated the characteristics of innovation using the theory of diffusion for the released improved groundnut varieties (Table 1).

We surveyed the characteristics of the various improved groundnut varieties, the time of their release, the source of the improved groundnut varieties, and how wide they were spread. We also surveyed a range of social characteristics based on studies that used the diffusion theory. The range of social characteristics was guided by the theory that different external and internal characteristics affect the farmers' decision in adopting the improved technology [18]. It was further revealed that the external and internal factors influencing the decision to adopt new technology in developing countries include age, gender, education, membership of a farmer group, farm size, grain price, seed availability, and seed accessibility [18]. The aforementioned factors have been used by other adoption 
studies, which applied the probit regression model [12,13,19-21]. This study has increased the number of potential factors in addition to the ones already used in the literature.

Table 1. Innovation characteristics against the improved groundnut varieties in a study area [21].

\begin{tabular}{cc}
\hline Innovation Characteristics & $\begin{array}{c}\text { Evaluation of the Innovation Characteristics in the Study Area } \\
\text { Relative advantage }\end{array}$ \\
$\begin{array}{c}\text { The performance of the improved varieties in terms of } \\
\text { productivity, market traits, drought compared to the old ones. }\end{array}$ \\
$\begin{array}{c}\text { The resources used in the production of improved varieties were } \\
\text { compared to used in the production of old varieties, such as land, } \\
\text { labour, hand hoes. }\end{array}$ \\
Complexity vs. Simplicity & $\begin{array}{c}\text { The efforts in terms of learning about improved varieties were } \\
\text { investigated in terms of simple, moderate, or hard to learn and use. }\end{array}$ \\
Trialability & $\begin{array}{c}\text { The study investigated if there are trials conducted such as } \\
\text { demo-farms, farmer research groups for improved varieties. }\end{array}$ \\
\hline Observability & $\begin{array}{c}\text { The study investigated if farmers were able to observe results } \\
\text { easily of using improved varieties by research farmer groups or } \\
\text { demo plots. How could the promised better results (compared to } \\
\text { the old varieties) be observed? }\end{array}$ \\
\hline
\end{tabular}

\subsection{Research Methodology}

The study was conducted from late January to early April 2019. We investigated all 17 varieties, which were gradually released from between the 1960s and 2018 by the Tanzania Agricultural Research Institute Naliendele (TARI-Naliendele, Mtwara, Tanzania). Farmers were surveyed in seven agro-ecological zones (South zone, Southern Highlands, Central Zone, Lake Zone, Nothern Highlands, Coastal Zone, and western Zone) across the country, to identify how far improved and recently released varieties spread across communities using the theory of diffusion. We surveyed social, economic, and demographic factors and other variables, namely age, sex, education, membership of a farmer group, farm size, grain price, seed availability, and seed accessibility, using a probit regression model. We surveyed the nature of innovation and communication channels, through which improved variety seeds are spread.

\subsubsection{Study Area, Site Selection and Sampling}

The study was carried in purposively 11 selected districts among the most productive groundnut districts in Tanzania. A four-stage stratified sampling was used with the importance of groundnut production and implementation of groundnut dissemination project as the main selection criteria. The first stratum was the administrative zone, the second stratum the region, the third one was the district and the fourth stratum was the village. In the 11 sampled districts, we selected nine villages where new varieties were introduced through project interventions (experimental villages) and two non-intervention villages without new variety introduction (control villages). The project interventions were implemented throughout Tropical Legumes III (TL III), which took place between 2007 and 2019. The TL III project introduced new and highly productive varieties to groundnut farming communities through increased seed production and popularization activities. The selection of the villages in both intervention and non intervention districts was also based on the importance of groundnut production. The project intervention villages included 18 villages, whereas the non-intervention villages were four. Per village, the list of groundnut farmers was put together with the help of extension officers. Thereafter, interviewed farmers were randomly selected. A total of 300 farmers were interviewed: 133 were female, and 167 were male. A total of 126 male farmers were from intervention districts, while 41 were from non-intervention districts. 


\subsubsection{Enumerators and Data Collection}

Data were collected by the first author. The author used an electronic platform, called MEASURE, where the semi-structured questionnaire was programmed to collect data. The questionnaire was pre-tested and amendments were made before data collection. Secondary data on the variety names, traits, expected yields, and time of release of the 17 varieties were also collected [8-10].

\subsubsection{Data Synthesis and Analysis}

After gathering qualitative and quantitative data on vaious factors described by the theory of diffusion, the descriptive statistics and probit regression model through STATA software version 13 were used to analyze data. Descriptive statistics encompassed the computation of means, ranges, ratios, percentages, and rates. The social, economic, and demographic characteristics studied included age, education level, land ownership, group belonging, and farm size. Farm size was categorized into two groups, farmers with less than 2 ha, classified as small-scale farmers, and those with 2 ha and above, classified as large-scale farmers [22].

For the Probit regression model, the dependent variable was a dummy variable $(0,1)$, which is the adoption of improved groundnut variety by a farmer, while the independent variables were age (continuous), gender $(0=$ female, $1=$ male), education (continuous), land ownership $(0=$ others, 1 = landlord), group membership ( $0=$ non-member, $1=$ member), farm size (continuous), experience (continuous), grain price (continuous), seed availability $(0=$ not available, $1=$ available) and seed cost (continuous). In adoption studies, many researchers have used the Probit, Logit, and Tobit models, which are binary statistical models that enable a specific analysis of farmers' adoption of new technology $[17,23]$. The three statistical models when used for analysis can provide more detailed information on the behaviour or characteristics of a farmer who adopts the improved technology [24]. The probit model is more suitable than the other static models, due to its outstanding properties, in particular, the assumption of normal distribution [25] (pp. 457-470). We used the probit regression model to identify the factors that affect the farmer's decision to adopt improved groundnut varieties (1).

Probit model:

$$
\begin{gathered}
Y_{i}=F\left(X_{i} \beta\right)+\mathcal{E}_{i} \\
Y_{i}=1 \text { if adopted, } 0 \text { otherwise }
\end{gathered}
$$

where $\mathcal{E} \sim \mathrm{N}(0,1) \beta$-maximum likelihood, $\mathrm{i}-$ cumulative distribution functions of standard normal distribution. $\varepsilon$-error term $\mathrm{x}$ —set of independent variables. Then, the marginal effect is (2).

$$
\frac{\partial \mathrm{E}\left(\frac{\mathrm{y}}{\mathrm{x}}\right)}{\partial \mathrm{x}}
$$

where $Y_{i}=$ dependent variable, that is the use of improved groundnut varieties, $X_{i}=$ independent variables (age, gender, education, group membership, farm size, grain price, seeds availability, seed accessibility). $\partial=$ change in probability of independent variable in a given change of dependent variable.

The empirical equations are (3) and (4).

$$
\begin{gathered}
P_{i}(0,1)=\beta_{0}+\beta_{1} X_{1}+\beta_{2} X_{2}+\beta_{n} X_{n}+e_{i} \\
P_{i}(0,1)=\beta_{0}+\beta_{1} X_{\text {Age }}+\beta_{2} X_{\text {gender }}+\beta_{3} X_{\text {Land ownership }}+\beta_{4} X_{\text {Farmsize }}+ \\
\beta_{5} X_{\text {Group membership }}+\beta_{6} X_{\text {education }}+\beta_{7} X_{\text {Experience }}+\beta_{8} X_{\text {Grain price }}+\beta_{9} X_{\text {seed availability }}+e_{i}
\end{gathered}
$$




\section{Results}

\subsection{Socio-Characteristics of the Sampled Groundnut Farmers}

Groundnut productivity in the study area is affected by the social, economic, and demographic characteristics of the farmers. In the intervention and non-intervention districts, male groundnut farmers represent $52.5 \%$ and $68.3 \%$, respectively (Table 2). Most groundnut farmers were aged between 35 and 50 years, followed by youth (20-25 years old) in intervention districts, and followed by old farmers in non-intervention districts. About $84.2 \%$ of the interviewed male farmers in the intervention districts and $92.1 \%$ in the non-intervention districts had primary school education level; very few farmers got secondary education. Additionally, for female farmers interviewed, $87.1 \%$ in intervention districts and $89.5 \%$ from non-intervention districts had primary education; very few female farmers got secondary education. Moreover, only interviewed farmers in intervention districts and none in non-intervention districts are organized in groups. However, $28.6 \%$ interviewed male farmers were organized in groups, which are fewer than female farmers, accounting for $51.7 \%$ of the total interviewed female farmers in intervention districts. In both intervention and non-intervention districts, $49.0 \%$ and $62.2 \%$ of interviewed female and male farmers were landlords, respectively. About 33.6\% of the interviewed male farmers in intervention districts and $42.6 \%$ in non-intervention districts were landlords. About 59.8\% of the interviewed male farmers from intervention districts were settlers, and $52.1 \%$ of the interviewed farmers in non-intervention districts were hiring land for farming. Around $15.1 \%$ of interviewed male farmers in intervention districts and $26.3 \%$ in non-intervention districts had a farm size larger than 2 ha. About $6 \%$ of female farmers interviewed in intervention districts and $21.1 \%$ of female farmers interviewed had a farm size larger than 2 ha.

Table 2. Characteristics of interviewed groundnut farmers $(n=300)$.

\begin{tabular}{|c|c|c|c|c|c|}
\hline \multirow[t]{2}{*}{ Variables } & \multirow[t]{2}{*}{ Categories } & \multicolumn{2}{|c|}{$\begin{array}{l}\text { Percentage (\%) of Respondents } \\
\text { in Intervention Districts }(n=240)\end{array}$} & \multicolumn{2}{|c|}{$\begin{array}{c}\text { Percentage }(\%) \text { of Respondents } \\
\text { in Non-Intervention Districts }(n=60)\end{array}$} \\
\hline & & Male $(n=126)$ & Female $(n=114)$ & Male $(n=41)$ & Female $(n=19)$ \\
\hline \multirow{5}{*}{ Age } & $<20$ & 0 & 0.80 & 0 & 0 \\
\hline & $20-35$ & 23.80 & 20.69 & 18.42 & 21.05 \\
\hline & $35-50$ & 49.20 & 53.45 & 39.47 & 47.37 \\
\hline & $50-65$ & 20.60 & 19.83 & 39.47 & 26.32 \\
\hline & $>65$ & 6.34 & 5.17 & 2.63 & 5.26 \\
\hline \multirow{4}{*}{ Education level } & Primary & 84.92 & 87.07 & 92.11 & 89.47 \\
\hline & Secondary & 7.93 & 5.17 & 2.53 & 0 \\
\hline & Postsecondary & 2.38 & 2.60 & 0 & 0 \\
\hline & No formal education & 3.96 & 5.17 & 5.26 & 10.52 \\
\hline \multirow{3}{*}{ Land ownership } & Settlers & 49.03 & 33.62 & 62.16 & 42.63 \\
\hline & Landlord & 45.01 & 59.48 & 36.84 & 52.11 \\
\hline & Both & 5.55 & 6.90 & 0.89 & 5.26 \\
\hline \multirow{2}{*}{ Group belonging } & Member & 28.57 & 48.28 & 0 & 0 \\
\hline & No-member & 71.42 & 51.72 & 100 & 100 \\
\hline \multirow{2}{*}{ Farm size (ha) } & $\leq 2$ & 84.92 & 29.31 & 73.68 & 78.94 \\
\hline & $>2$ & 15.08 & 6.03 & 26.32 & 21.05 \\
\hline
\end{tabular}

\subsection{Features of the Innovation from Farmer Views}

Groundnut farmers were able to evaluate the improved varieties based on the five innovation features. About $18 \%$ of the interviewed farmers explained that improved varieties were more resistant to drought compared to the old ones. About $17 \%$ of the interviewed farmers reported that the improved varieties were on average $40 \%$ more productive than the old ones. Around $10 \%$ of the interviewed farmers mentioned that improved varieties were more marketable than the old ones (Table 3). The findings further indicate that improved varieties used similar resources, like those of old varieties, namely land, labour, and hand hoe, without incurring more cost of investment. About 55\% of interviewed farmers explained that it was simple to learn the names, colour, and features of most improved varities, although some of the varieties were a bit similar in colour, such as the Pendo 1998 
and Mangaka 2009. In the intervention villages, demonstration plots, trial farms and research farms were established for for farmers to learn by observation. Groundnut farmers were able to observe the production process and other benefits like ability to resist to diseases, such as leaf spot or rosette.

Table 3. Features of the innovation (improved varieties) based on farmer views $(n=300)$.

\begin{tabular}{cc}
\hline Variables & \% of Farmers \\
\hline High productivity of improved variety & 17 \\
Resistance to diseases & 18 \\
Simplicity to learn on improved & 55 \\
Market value & 10 \\
Total & 100 \\
\hline
\end{tabular}

\subsection{The Communication Channel through Which Farmers Get Information on Improved Groundnut Farmers}

Farmers received information from six main sources. About $50 \%$ of farmers received information on the improved groundnut varieties from their fellow farmers in a group, and $30 \%$ received information from the Research Institute (Table 4). The extension services and neighbors were used by $10 \%$ of the interviewed farmers each. Mobile phones and seed companies were used by 7 and $2 \%$ of the interviewed farmers, respectively (Table 4).

Table 4. The communication channels through which farmers receive information about seeds $(\mathrm{n}=300)$.

\begin{tabular}{cc}
\hline Communication Channel & \% of Farmers Using the Channel \\
\hline Farmers in groups & 50 \\
TARI-Naliendele research centre & 20 \\
Extension service & 11 \\
Neighbours & 10 \\
Mobiles phones & 7 \\
Seed company & 2 \\
Total & 100 \\
\hline
\end{tabular}

\subsection{Market Traits and Yield Performance of Improved Varieties Released Since the 1960s}

A total of 17 varieties of groundnut were gradually released in Tanzania by TARI-Naliendele. The yield performance of the improved varieties ranged from $1100 \mathrm{~kg} / \mathrm{ha}$ to $2000 \mathrm{~kg} / \mathrm{ha}$, while the minimum on station yield ranged from $1050 \mathrm{~kg} / \mathrm{ha}$ to $1500 \mathrm{~kg} / \mathrm{ha}$ (Table 5). The yield performance between on-station management and under farmer management is still wide (400 to $700 \mathrm{~kg} / \mathrm{ha}$ ). Among all varieties, Nachi 2015 is the most consistent high yielding variety, ranging from 1100 to $1500 \mathrm{~kg} /$ ha across all agro-ecological conditions. The yield range captured the productivity range from all agro-ecologies in the country.

Table 5. Improved varieties released and their attributes and yield potential in $\mathrm{kg} / \mathrm{ha} \mathrm{[24-26].}$

\begin{tabular}{|c|c|c|c|c|c|}
\hline \multirow[b]{2}{*}{ Variety } & \multirow[b]{2}{*}{ Year of Release } & \multirow[b]{2}{*}{$\begin{array}{c}\text { Top 3-5 Agronomic, Genetic, } \\
\text { Market Attributes }\end{array}$} & \multicolumn{3}{|c|}{ Expected Yield (kg/ha) } \\
\hline & & & $\begin{array}{l}\text { Max. on } \\
\text { Station }\end{array}$ & $\begin{array}{l}\text { Min. on } \\
\text { Station }\end{array}$ & $\begin{array}{l}\text { Under Farmer } \\
\text { Management }\end{array}$ \\
\hline Mtwaranut 2016 & 2018 & $\begin{array}{l}\text { Medium maturity, groundnut } \\
\text { rosette, tan in colour, large in size, } \\
\text { drought tolerant }\end{array}$ & 1300 & 1100 & 1040 \\
\hline Tanzanut 2016 & 2018 & $\begin{array}{l}\text { Medium maturity, groundnut } \\
\text { rosette, large in size, tan in colour, } \\
\text { drought tolerant }\end{array}$ & 1500 & 1200 & 1095 \\
\hline Naliendele 2016 & 2018 & $\begin{array}{l}\text { Medium maturity, tolerant to } \\
\text { diseases and drought, bold size, red } \\
\text { colour, high oil content }\end{array}$ & 1500 & 1200 & 1050 \\
\hline
\end{tabular}


Table 5. Cont.

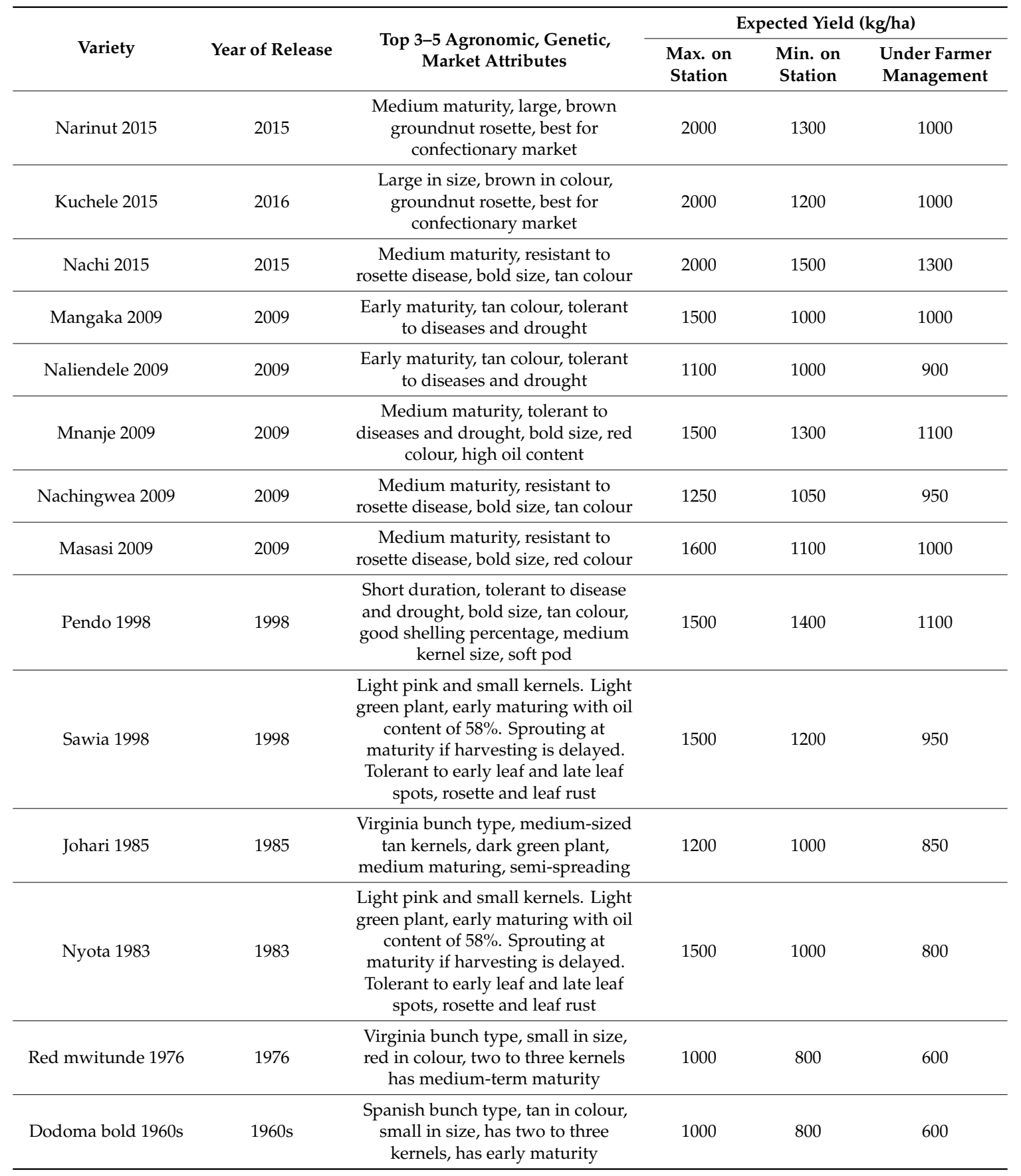

3.5. Actual Varieties of Groundnut in Farmers' Fields and Variation of Farmer's Preferences across Zones and Regions

Among the improved groundnut varieties released in Tanzania, farmers make specific choices, which are mostly related to the grain demand market in their location (Table 6). The trait preferences for improved groundnut varieties tend to be similar in most neighbouring regions. For example, the Mtwara and Lindi regions were producing Johari 1985 and Pendo 1998. Of the 17 varieties, only six were identified by their known release names among interviewed farmers, namely, Johari 1985, Pendo 1998, Naliendele 2009, Mnanje 2009, Mangaka 2009, and Nachi 2015. Some of the groundnut improved varieties like Sawia 2009, Masasi 2009, Red mwitunde 1976, and Nyota 1983, were not mentioned among interviewed farmers. The more recently released varieties, namely: Kuchele 2015, 
Narinut 2015, Mtwaranut 2016, Naliendele 2016, and Tanzanut 2016 are reported to be in a seed multiplication process by seed producers, but not yet with farmers. It was observed that farmers are conscious of improved groundnut varieties they produce, but often mix up names due to similarities in colour and size. Groundnut varieties like Pendo 1998 and Johari 1985 are similar in red coloured and size but different in their genetic traits, which cannot be easily seen by the naked eye to all farmers (Table 6). In non-intervention districts, the interviewed farmers stated to be involved in the production of only old varieties identified by local names such as Kongwabush in Mpwapwa district and Seleman in Mkalama district in Singida region (Table 6).

Table 6. Variation of the preferences of groundnut attributes throughout zones and regions $(n=300)$.

\begin{tabular}{ccc}
\hline Zone & Region & Preference by Attributes with a Specified Variety \\
\hline \multirow{2}{*}{ South } & Mtwara & Medium size tan (Pendo, Johari), red large (Mnanje 2009) \\
& Lindi & Medium size tan (Pendo, Johari) \\
\hline \multirow{5}{*}{ South Highlands } & Mbeya & Large tan (Nachi 2015), red large (Mnanje 2009) \\
& Iringa & Large tan (Nachi 2015), red large (Mnanje 2009) \\
& Njombe & Large tan (Nachi 2015), red large (Mnanje 2009) \\
& Rukwa & Large tan (Nachi 2015), red large (Mnanje 2009) \\
& Ruvuma & Large tan (Nachi 2015), red large (Mnanje 2009) \\
& Songwe & Large tan (Nachi 2015), red large (Mnanje 2009) \\
& Katavi & Large tan (Nachi 2015), red large (Mnanje 2009) \\
\hline \multirow{2}{*}{ Central } & Dodoma & Medium size tan (Pendo), Medium red (Dodoma bold) \\
& Singida & Local variety, red (known as Seleman) \\
\hline \multirow{2}{*}{ Coastal } & Dar-es-Salam & Medium tan (Pendo, Johari), red large (Mnanje 2009), Medium red \\
& Morogoro & (Dodoma bold), large white (Nachi 2015) \\
& Medium tan (Pendo, Johari), Red large (Mnanje 2009), Medium red \\
\hline \multirow{2}{*}{ Northern highlands } & Kilimanjaro & Red large (Mnanje 2009), Medium tan (Dodoma bold) \\
& Manyara & Red large (Mnanje 2009), Medium tan (Dodoma bold) \\
& Kagera & Medium tan (Pendo, Johari), Large red (Mnanje 2009) \\
\hline \multirow{2}{*}{ Lake } & Geita & Medium tan (Pendo, Johari), large white (Nachi 2009) \\
\hline \multirow{2}{*}{ Western } & Kigoma & Medium tan (Pendo, Johari), large tan with high oil content \\
& Tabora & Medium tan (Pendo, Johari), large tan with high oil content \\
\hline
\end{tabular}

\subsection{Rate of Adoption of Improved Groundnut Varieties}

The findings indicate that the adoption rate is correlated with the time of release. Varieties that were released earlier have a higher adoption rate than the most recent ones. This is the case for the variety Pendo released in 1998 with with an adoption rate of $17.1 \%$. The varieties Mnanje and Mangaka both released in 2009 have an adoption 5.4\% each. The varieties Naliendele and Nachi released in 2009 and 2015, respectively, had the lowest adoption rate which was below 1\%. The exception was Johari released in about 35 years ago, but was only adopted by about $6 \%$ of farmers. The finding also showed that there was no adoption of improved varieties in non-intervention districts (Table 7). The project interventions seem to be the main channel through which the improved varieties of groundnut are made avalaible to farming communities.

Although the adoption figure per variety is low, the overall adoption of improved varieties is about $35 \%$ in the district that underwent project interventions. 
Table 7. Adoption rate per variety among farmers in intervention districts $(n=300)$.

\begin{tabular}{cccc}
\hline Variety & Year of Release & $\begin{array}{c}\text { Adoption Rate (\%) by Respondents } \\
\text { in Intervention Districts }(\boldsymbol{n = 2 4 0 )}\end{array}$ & $\begin{array}{c}\text { Adoption Rate (\%) by Respondents } \\
\text { in Non-Intervention Districts }(\boldsymbol{n}=\mathbf{6 0})\end{array}$ \\
\hline Nachi & 2015 & 0.42 & - \\
Naliendele & 2009 & 0.83 & - \\
Mnanje & 2009 & 5.42 & - \\
Mangaka & 2009 & 5.42 & - \\
Pendo & 1998 & 17.08 & - \\
Johari & 1985 & 5.82 & - \\
Total & & 35 & - \\
\hline
\end{tabular}

\subsection{Factors that Influence the Adoption of Improved Groundnut Varieties}

The estimated outputs through the probit model are presented in Table 8. The estimate of the empirical results was conducted through the maximum likelihood method, with the model being significant $(p<0.1)$. Additionally, the $\chi^{2}$ (Prob $\left.<0.000\right)$ showed that the likelihood ratio statistic was significant, which implies that the explanatory power of the model was strong. From the Probit regression model, the variables age, gender, group membership, availability of seed were found to be positive and significant in influencing the decision of the farmer to adopt improved varieties of groundnut. Seed cost was also significant but negative in influencing farmer adoption decision. Though having mixed effects, variables like land ownership, farmer acreage, education levage, farming experience, and grain price were not significant.

Table 8. Probit regression result of determinants of adoption of improved varieties.

\begin{tabular}{ccccc}
\hline Variables & Coefficient & Std. Err & Z & $p>|\mathbf{z}|$ \\
\hline Age (continuous) & 0.0162 & 0.0069 & 1.54 & $0.023^{* *}$ \\
Gender (0 = Female, 1 = Male) & 0.6268 & 0.1944 & 3.22 & $0.001^{* * *}$ \\
Land ownership (0 = Others, 1 = Landlord) & -0.075 & 0.1826 & -0.14 & 0.681 \\
Group membership (0 = non-member, 1 = member) & 0.4114 & 0.2132 & 1.93 & $0.054^{* *}$ \\
Farmer acreage (continuous) & -0.0003 & 0.0031 & -0.11 & 0.323 \\
Education level (continuous) & 0.0035 & 0.0036 & 0.99 & 0.913 \\
Experience (continuous) & 0.0447 & 0.0346 & 1.29 & 0.197 \\
Grain price (continuous) & 0.00002 & 0.0003 & 0.75 & 0.452 \\
Availability of improved seed (0 = not available, 1 = Available) & 1.2258 & 0.2654 & 4.62 & $0.002^{* * *}$ \\
Seed cost (continuous) & -0.0002 & 0.0007 & 2.75 & $0.006^{* * *}$ \\
Constant & -1.93 & 0.3897 & -4.95 & 0 \\
\hline
\end{tabular}

$n=300$, LH $\chi^{2}(10)=72.54$, Prob $<0.000$, Pseudo $\mathrm{R}^{2}=0.2127 .{ }^{* *}$ Significant at $1 \%,{ }^{* *}$ Significant at $5 \%$.

Post estimation of the probit equation results was done and marginal effects were obtained as shown in Table 9.

Table 9. Marginal effects on determinants of adoption of improved groundnut varieties.

\begin{tabular}{ccccc}
\hline Variables & Marginal Effect & Std. Err & $\mathrm{Z}$ & $p>|\mathrm{Z}|$ \\
\hline Age & 0.2011 & 0.0601 & 3.24 & 0.067 \\
Gender & 0.1703 & 0.0509 & 3.35 & 0.001 \\
Group membership & 0.1117 & 0.0572 & 1.95 & 0.015 \\
Availability of improved seed & 0.333 & 0.0643 & 5.18 & 0.001 \\
Seed cost & -0.0029 & 0.0019 & 1.55 & 0.12 \\
\hline
\end{tabular}

The coefficient for age was 0.2011 , implying that an increase in age of the farmer by one year, increases the probability of farmer adoption of improved groundnut improved varieties by $20 \%$. The coefficient for gender was 0.1703 , implying that being male increases the probability of farmer adoption by $17 \%$. The estimated marginal effect for group membership was 0.1117 , implying that 
being in a group increase the chance of adopting groundnut varieties by $11 \%$. The estimated marginal effect of availability of seed was 0.333 , implying that a $1 \%$ increase in improved seed availability among groundnut farmers will lead to a likely increase in the adoption of improved varieties by $33 \%$. The estimated coefficient for seed cost was -0.0029 , implying that a unit increase in seed cost would decrease the probable adoption of groundnut improved variety by $0.3 \%$. The positive marginal effects of age, gender, group membership, and availability of improved seed and the negative value for seed cost represent important hints for future interventions and policy focus.

\section{Discussion}

To increase farm productivity, employment, food, and nutritional security, the seed of improved groundnut varieties is one of the most appropriate inputs [26]. The use of improved seed is a critical component of agriculture and in groundnut production systems [23]. The findings show that the production of groundnut increases as the age increases in both intervention and non-intervention districts. However, in the old age of years above 50, only a few farmers can persist in production, because it is a labour-intensive type of farming [9]. Groundnut production employed both women and youth, who are the most neglected groups in other income-generating crops like rice and tobacco [5,26]. The older females in both groups were subject to low education compared to male farmers. These results are similar to the findings in the national census where females were $7 \%$ less literate than males [14]; this negatively affects womens decision in adopting new technologies. The majority of farmers produced groundnut on small farm sizes of less than 2 ha. These smallholder farmers cannot afford to invest in productive technologies that are easily taken up in large farming $[4,13]$. Other authors explain that farmers who produce at large scale can benefit from economies of scale, adopt improved variety, and observe good agronomic practices [27]. The majority of farmers was not aware that the improved groundnut varieties performed better than old groundnut varities by productivity, market, and resistance to drought and diseases. These results are consistent with previous findings in Tanzania [28].

The findings showed that farmers received information four ways, namely TARI-Naliendele, neighbours, extensionists, and farmer group members. Among the four communication channels, an information through a group member was the most popular channel. These results are similar to those found in Nigeria, which determined the popular method of communicating improved varities [20]. The authors found that a farmer hearing information from a member from his/her own group increased the adoption of improved varieties. In the study area, few $(28 \%)$ of the interviewed farmers were organized into groups.

About $78 \%$ of seeds were distributed by farmer groups who were legally unable to sell beyond their districts. Seed companies with the ability to distribute seeds beyond their districts account for below $1 \%$ of the total amount of seed farmers need [6]. The skewed dependency on farmer groups channel impedes the sustainable and timely distribution of improved seeds within farming communities. These farmer groups are organized in such way that they select their farm for seed production and on-field demonstrations together. The local agricultural district officers inspect and monitor the seed production on behalf of the Tanzania Official Seed Certification Institute (TOSCI). After seed production, the group members divide the harvested seed among themselves for every individual to continue seed production on their own farm. Part of the seed is retained for continued production as a group and the remaining seed is sold to fellow farmers as a Quality Declared Seed (QDS). These farmer groups obtain their basic seeds from TARI-Naliendele, the research institute mandated for groundnut research nationwide. These farm groups select the varieties with interesting traits after promotion by TARI-Naliendele. The newer varieties are made available to farmer groups in this way. Farmers who participate in new variety trials are allowed to keep the seed for their use and informal distribution. Allowing the farmers to keep the seed from trials is observed to be one of the best ways to accelerate the adoption of improved varieties. 
The findings showed that the improved groundnut varieties have higher yield compared to old varieties. Farmers produce an average of $745 \mathrm{~kg} / \mathrm{ha}$, which is way below the productivity range of improved varieties like Nachi 2015, Mnanje 2009 [11]. The use of old varieties by farmers has been reported as one of the major causes of low productivity in smallholder farming systems [3]. Furthermore, the limited extension service toward farmers is another cause for low productivity [26]. The findings further showed the high market demand for recently released groundnut varieties. This corroborates previous studies that Tanzania purchases about $10 \%$ of groundnut produced in Malawi, where recent varieties are readily available [11]. These varieties imported from Malawi are Mnanje 2009 and Nachi 2015. The information asymmetry among groundnut value chain actors partly justifies the inability of farmers to identify sources of the seed of recently released varieties [3].

The findings showed that old varieties such as Pendo 1998 have higher adoption rates than recent varieties. Higher adoption rates of old varieties than the recent ones imply that the communication around new improved varieties is slow to reach the social system [21]. In the intervention areas, old varieties, particularly Pendo 1998, were very popular, because, after release, they benefitted from intensive promotion activities in the early 2000s. However, because Pendo 1998 was highly susceptible to rosette disease, Mangaka 2009 was released in 2009, being less susceptible to rosette diseases.

It was observed that male farmers between 35 and 50 years old adopt improved groundnut varieties more than females. The results are similar to the studies that argued that male farmers can easily adopt improved groundnut varieties because they are the major household decision-makers on resource allocation [29], and, most importantly, more exposed to technologies than the female counterpart. Indeed, societies in Tanzania are of the patrilineal type, in which the family heritage belongs to males, and the major social-economic decisions are made by males [14]. Hence, men are in charge of decision making and can easily decide on the adoption of improved varieties. Farmers aged between 35 and 50 years were found to use more improved seeds than all other age classes. These results are contrary to the expectation since older farmers are said to be more conservative in adopting new technology. However, the study results are similar to those who noted that older farmers easily adopt improved varieties based on their vast experiences on various stresses affecting groundnut production [30]. Tanzania has recently experienced an increasing drought due to climate changes, market changes, and biotic and abiotic stresses [2]. This may justify the fact that older farmers can easily compare the changes through their experiences and adopt improved varieties more readily than the other age classes.

The study further showed that group membership was positive and significant as expected for improved variety adoption. It implies that as farmers join the professional farming groups, their ability to adopt improved groundnut varieties increases. The group membership ensures cohesiveness, good mandate, resources availability, integrity, access to relevant information and managerial capacity to members [31]. This finding is similar to the observation among smallholder farmers in Malawi [32]. In Malawi, farmers in groups were able to benefit not only from the shared knowledge among peers regarding modern farming methods, but also from economy of scale in accessing input markets as group. Hence, such farmers become good adopters of improved varieties. It was further explained that farmers who belong to an organized group usually have opportunities to access quick support from the government, NGOs, donors, and other stakeholders [33]. In Tanzania, there are similar cases in which farmers in groups are supported with seeds from research and development organizations [3]. Finally, seed availability and seed prices were observed significantly influence the adoption of improved groundnut varieties. Seed availability had a positive sign, whereas seed price had a negative sign, as expected. It implies that the availability of improved groundnut seeds among farmers in Tanzania at low cost increases the ability of farmers to adopt the improved groundnut varieties [34] (pp. 34-40).

\section{Conclusions}

Improved groundnut varieties are an innovation worthy of being distributed throughout the country, and farmer groups can be one of the best communication channels to do so. Old groundnut 
varieties are less productive than improved and recently released ones. The market demand for improved varieties is higher than that of the old ones. Effective adoption of improved groundnut varieties is required to ensure sufficient supply of food and income to farmers and non-farmers. The present study analyzed factors influencing preferences and adoption of improved groundnut varieties among farmers in Tanzania. The study concluded that the overall adoption of improved groundnut varieties was still low. The factors found to influence the adoption of improved of groundnut varieties were age, gender, education, land ownership, group membership, farm size, experience, grain price, seed availability, and seed cost. The factors age, gender, group membership, and seeds availability have a significant and positive influence on farmers' decision to adopt improved ground varieties in Tanzania. However, seed cost was significant, but negatively influencing their adoption. Based on these findings, the following measures were recommended. First, an integrated seed sector development approach, with a comprehensive strategy developed by stakeholders, would sustainably enhance access to quality seed of recently released varieties in both intervention and non-intervention areas. The promotion of the recently released varieties along with complementary agronomic practices simultaneously would incentivize farmers. Second, research, extension, and development organizations could make a difference by communicating at scale about the released groundnut varieties to all stakeholders. This will allow farmers to easily identify quality seed sources. Third, the deployment of labour-saving machinery would enable old farmers to easily manage the labour intensity to grow groundnuts and earn their living. Fourth, the enactment of good policy within the groundnut seed sector, such as comprehensive seed subsidy, will attract more seed companies to invest in groundnut seed production to ensure a wide and timely distribution of seeds. Groundnut farmers will then use improved groundnut seed, reduce abiotic and biotic stresses, and generate economic benefits. Such a policy would incentivize private businessmen and women to invest in seed and the entire commodity value chain across the country, based on the market and farmers' demands.

Author Contributions: Questionnaire preparation, E.A. and G.A.L.; Tool pre-testing, E.A., A.M., G.M. and S.M.; Data collection process, S.M., A.M., G.A.L. and E.A.; Data cleaning and analysis, S.M., G.A.L., E.A.; Draft preparation, S.M. and E.A.; Draft review and editing, R.V. (Ronnie Vernooy), R.V. (Rajeev Varshney), C.O., E.N., G.O., G.M. All authors have read and agreed to the published version of the manuscript.

Funding: This research was undertaken as part of, and funded by the CGIAR Research Program on Grain Legumes and Dryland Cereals (GLDC) and supported by CGIAR Fund Donors. Funding support for this study was provided by the International Crops Research Institute for the Semi-Arid Tropics through the Tropical Legume project, grant number: OPP1114827, by the Bill and Melinda Gates Foundation.

Acknowledgments: The authors are thankful to ICRISAT for funding and supporting the research. We thank TARI-Naliendele for administrative facilitation during the period of the study. We also thank the officials in all the districts in which data were collected for their cooperation in implementing the data collection phase. Finally, we thank the farmers for providing their information during data collection.

Conflicts of Interest: The authors declare no conflict of interest.

\section{References}

1. International Labour Organization (ILO). Research Department Trend Econometric Models, November 2015. Available online: http.//www.ilo.org/wcmsp5/groups/public/-dgreports (accessed on 5 July 2020).

2. Zurich, E. Historical drought trends revisited. J. Clim. Sci. 2014, 491, 338-339.

3. Daudi, H.; Hussein, S.; Mark, D. Groundnut production constraints, farming systems, and farmer-preferred traits in Tanzania. J. Crop Improv. 2018, 32, 812-828. [CrossRef]

4. National Bureau of Statistics. Tanzania Annual Agriculture Sample Survey Crop and Livestock Report. 2017. Available online: www.go.tz (accessed on 2 July 2020).

5. Food and Agriculture Organization. Statistical Data on Crops, Groundnut, Area, Production Quantity of Tanzania, Africa and the World. 2018. Available online: http://Faostat.fao.org (accessed on 17 January 2019).

6. Daudi, H.; Mashamba, P.; Mfaume, J.; Monyo, E.; Mponda, O. Groundnut breeding status. In Proceedings of the Annual Meeting-Tropical Legume 1 Phase 2 of Generation Challenge Programme, Addis Ababa, Ethiopia, 7-11 May 2012. 
7. Ndabila, A. Adoption of a System of Rice Intensification and Effect on Yield in Mbarali District Mbeya, Tanzania. Master's Thesis, Sokoine University of Agriculture, Morogoro, Tanzania, 2018.

8. United Republic of Tanzania. Press Release Report, Ministry of Agriculture and Fisheries on Improved Seeds Released in Tanzania. 2016. Available online: file://C:/Users/ICTSERVICES/Downloads/PRESS_RELEASE\% 202018.pdf. (accessed on 1 January 2020).

9. United Republic of Tanzania. Annual Report, Ministry of Agriculture Food Security and Cooperative on Improved Agricultural Research Technologies Recommended in Tanzania. 2007. Available online: https://www.kilimo.go.tz/uploads/Improved_Technologies.pdf (accessed on 1 January 2020).

10. United Republic of Tanzania. Press Release Report, Ministry of Agriculture and Fisheries on Improved Released Seed Varieties in Tanzania. 2018. Available online: https://www.kilimo.go.tz/index.php/sw/ highlights/view (accessed on 1 January 2020).

11. African Institute of Cooperate Citizenship (AICC). Malawi Groundnut Outlook. 2016. Available online: www.aiccafrica.org (accessed on 27 February 2020).

12. Mwakimata, R. Analysis of Gender Yield Gape Among Groundnut Farmers in Tanzania. Master's Thesis, Sokoine University of Agriculture, Morogoro, Tanzania, 2017.

13. Akpo, E.; Muricho, G.; Lukurugu, G.; Opie, H.; Ojiewo, C.; Varshney, R. Legume seed production for sustainable seed supply and crop productivity: Case of groundnut in Tanzania and Uganda. J. Crop Improv. 2020, 34, 518-539. [CrossRef]

14. United Republic of Tanzania. Census General Report, Population Distribution by Administrative Area. 2013. Available online: http://www.tzdpg.or.tz. (accessed on 17 October 2019).

15. Tanzania Peanut Processing. 2012. Available online: https://www.shellingmachine.com (accessed on 28 February 2020).

16. Isham, J. The effect of social capital on fertilizer adoption: Evidence from rural Tanzania. J. Afr. Econ. 2002, 1, 39-60. [CrossRef]

17. Abady, S.; Hansen, M.; Mesfin, H. Determinants of multiple groundnut technology adoptions in eastern Ethiopia. J. Rev. Agric. Econ. 2016, 19, 51-60.

18. Nasiru, A. Socio-Economic Factors Influencing the Adoption of Improved Rice Processing Technologies by Women in Jigawa State, Nigeria. Master's Thesis, Department of Agricultural Economics and Rural Sociology, Ahmadu Bello University, Zaria, Nigeria, 2014.

19. Oladele, O.I.; Kolawole, A. Ex-ante adoption of Sawah rice production technology in Kwara State Nigeria. Life Sci. J. 2013, 10, 2740-2745.

20. Asante, B.O.; Afari-sefa, V. Sarpong, D.B. Determinants of small scale farmers' Decision to Join Farmers' based organisations in Ghana. Afr. J. Agric. Res. 2011, 6, 2273-2279.

21. Rogers, E.M. Diffusion of Innovation, 3rd ed.; Colliner Macmillan Publisher: London, UK, 1995; p. 518.

22. Donkor, E.; Owusu, V.; Sekyele, E.; Ogundeji, A. The adoption of farm innovations among rice producers in Northern Ghana: Implications for sustainable rice supply. J. Agric. 2018, 8, 121. [CrossRef]

23. Chapoto, A.; Namonje-Kapembwa, T. Improved Agricultural Technology Adoption in Zambia: Are Women Farmers Being Left Behind? Working Paper 106; Indaba Agricultural Research Institute: Lusaka, Zambia, 2016; pp. 1-31.

24. Feder, G.; Just, R.E.; Zilberman, D. Adoption of agricultural innovations in developing countries. J. Econ. Dev. Cult. Change 1985, 33, 255-297. [CrossRef]

25. Wooldridge, J.M. Econometric Analysis of Cross-Section Data and Panel Data; Goron, P., Ed.; The MIT Press: Cambridge, MA, USA; London, UK, 2010; pp. 457-470.

26. Arborgast, G.; Mangasini, A.; Mwanahawa, L.; Neema, P. Socio-economic factors limiting smallholder groundnut production in tabora region. J. Repoa 2014, 14, 1-53.

27. Ajeigbe, A.; Amado, A.; Echekwu, A.; Ndjeunga, J.; Ntare, B.; Ibroand, A. Adoption and Impacts of Modern Groundnut Varieties in Nigeria. 2013. Available online: http://grainlegumes.cgiar.org (accessed on 13 October 2019).

28. Patric, A. Determinants of Derived Demand for Improved Maize Seeds in Rural Mainland Tanzania. Master's Thesis, Sokoine University of Agriculture, Morogoro, Tanzania, 2015.

29. Doss, C.; Morris, M. How does gender affect the adoption of agricultural innovations? The case of improved maize technology in Ghana. Agric. Econ. 2000, 25, 27-39. [CrossRef]

30. Kansiime, M.; Wambugu, S.; Shisanya, C. Determinants of farmers' decisions to adopt adaptation technologies in Eastern Uganda. J. Econ. Sustain. Dev. 2015, 6, 1-32. 
31. Tripp, R. Strategies for seed system development in sub-Saharan Africa: A case of Kenya, Malawi, Zambia and Zimbabwe. SAT eJ. 2006, 2, 1-47.

32. Tchale, H. The efficiency of smallholder in Malawi. Afr. J. Agric. Resour. Econ. 2009, 3, 101-121.

33. Mwaura, F.M.; Tungani, J.O.; Sikuku, D.; Woomer, P.L. Acceptability of cereal banks as a marketing intervention among smallholders in western Kenya. Outlook Agric. 2012, 41, 35-40. [CrossRef]

34. Freidman, D.D. Price theory: An Intermediate Text, 2nd ed.; South-Western Publishing Co.: Cincinnati, $\mathrm{OH}$, USA, 1990; pp. 34-40. 